\title{
Proteomics of Canine Lymphoma Identifies Potential Cancer- Specific Protein Markers
}

\author{
Dudley L. McCaw, ${ }^{1}$ Arvan S. Chan, ${ }^{2}$ Andrew L. Stegner, ${ }^{2}$ Brian Mooney, ${ }^{3}$ Jeffrey N. Bryan, ${ }^{1}$ \\ Susan E. Turnquist, ${ }^{4}$ Carolyn J. Henry, ${ }^{1,5}$ Hannah Alexander, ${ }^{2}$ and Stephen Alexander ${ }^{2}$
}

\begin{abstract}
Purpose: Early diagnosis of cancer is crucial for the success of treatment of the disease, and there is a need for markers whose differential expression between disease and normal tissue could be used as a diagnostic tool. Spontaneously occurring malignancies in pets provide a logical tool for translational research for human oncology. Lymphoma, one of the most common neoplasms in dogs, is similar to human non - Hodgkin's lymphoma and could serve as an experimental model system.

Experimental Design: Thirteen lymph nodes from normal dogs and 11 lymph nodes from dogs with B-cell lymphoma were subjected to proteomic analysis using two-dimensional PAGE separation and matrix-assisted laser desorption/ionization time-of-flight analysis.

Results: A total of 93 differentially expressed spots was subjected to matrix-assisted laser desorption/ionization time-of-flight tandem mass spectrometry analysis, and several proteins that showed differential expression were identified. Of these, prolidase (proline dipeptidase), triosephosphate isomerase, and glutathione $S$-transferase were down-regulated in lymphoma samples, whereas macrophage capping protein was up-regulated in the lymphoma samples.

Conclusions: These proteins represent potential markers for the diagnosis of lymphoma and should be further investigated in human samples for validation of their utility as diagnostic markers.
\end{abstract}

Spontaneously occurring malignancies in pets provide a logical tool for translational research in human oncology (1). Companion animals are exposed to similar environmental conditions and carcinogens as humans. For example, similar genetic changes leading to cancer have been found in dogs and humans as in the case of renal cancer $(2-4)$. The completely sequenced dog genome is predicted to contain 19,300 protein-coding genes and nearly all are homologues of human genes (5). However, little work has been done to date on using this useful system for identifying molecular markers for cancer.

Lymphoma is one of the most common neoplasms in dogs and is similar to human non-Hodgkin's lymphoma. In dogs, the multicentric form involving peripheral lymph nodes is the

\footnotetext{
Authors' Affiliations: ${ }^{1}$ Department of Veterinary Medicine and Surgery, ${ }^{2}$ Division of Biological Sciences, ${ }^{3}$ Proteomic Center, Christopher S. Bond Life Sciences Center, ${ }^{4}$ Department of Veterinary Pathobiology, Veterinary Medical Diagnostic Laboratory, and ${ }^{5}$ School of Medicine, University of Missouri, Columbia, Missouri Received 11/13/06; revised 1/28/07; accepted 1/31/07.

Grant support: University of Missouri Research Board grant RB 03-083 and NIH grant GM53929 (S. Alexander and H. Alexander).

The costs of publication of this article were defrayed in part by the payment of page charges. This article must therefore be hereby marked advertisement in accordance with 18 U.S.C. Section 1734 solely to indicate this fact.

Note: Current address for S.E. Turnquist: Pfizer, Inc., Kalamazoo, MI 49001

Requests for reprints: Dudley L. McCaw, Department of Veterinary Medicine and Surgery, University of Missouri, Clydesdale Hall, 379 East Campus Drive, Columbia, MO 65211. Phone: 573-882-7821; Fax: 573-884-5444; E-mail: McCawD@missouri.edu.

(C) 2007 American Association for Cancer Research.

doi:10.1158/1078-0432.CCR-06-2699
}

most common form, but disease can arise from any tissue. As with non-Hodgkin's lymphoma, canine lymphoma can be either B or T cell, but most of the peripheral lymphomas are B cell (6). Canine lymphoma has a reported annual incidence of 25 of 100,000 dogs per year and accounts for $5 \%$ of all malignant neoplasms in the dog (6). In humans, the B-cell lymphoid neoplasm incidence is reported to be 26 of 100,000 per year (7). Canine non-Hodgkin's lymphoma is comparable clinically and histologically with intermediate and high-grade non-Hodgkin's lymphoma in humans $(1,8)$. It is a reasonable model for comparison with human non-Hodgkin's lympho$\mathrm{ma}$ as it is a common, nonviral-associated, spontaneous tumor. Canine lymphoma is advantageous for study compared with humans in that average remission times are shorter than 1 year, thus facilitating rapid accrual of data. Surgical removal of affected lymph nodes and histopathologic analysis are a routine part of therapy, and canine lymphoma is treated with the same drugs as human lymphoma, most commonly vincristine, cyclophosphamide, L-asparaginase, doxorubicin, and prednisone (9). These considerations, taken together with the availability of samples, make the dog an excellent candidate for proteomic-based research on cancer.

Proteomics is one of a variety of approaches that are currently in use for the identification of the molecular changes that accompany the progression of neoplastic disease. It is now widely used and strongly complements gene expression approaches (10) but has not previously been used to study canine cancer. Proteomic approaches have the advantage that they can identify changes in protein isoforms and posttranslational modifications that are common in cancer and go 
undetected by microarray analyses of RNA expression. In the following study, we report the results of a comparative proteomic analysis of 13 lymph nodes from normal dogs and 11 lymph nodes from dogs with B-cell lymphoma and the identification of several differentially expressed protein markers.

\section{Materials and Methods}

Animals. The experimental protocol for the nondiseased control dogs was approved by the University of Missouri-Columbia Animal Care and Use Committee, and the dogs were obtained through the Office of Animal Resources. Five mature, male, nonconditioned, random source, mixed breed dogs were obtained. The dogs appeared healthy based on physical examination. On arrival to our facility, the dogs were anesthetized with sodium pentobarbital and lymph nodes were removed. In accordance with the approved protocol, the dogs were euthanatized immediately after the removal of the lymph nodes and before recovery from anesthesia. Euthanasia was accomplished by the use of pentobarbital sodium (Vortech, Dearborn, MI). In each case, we removed the superficial, peripheral, lymph nodes (prescapular and popliteal) because these are most often removed for biopsy in lymphoma cases. A portion of each lymph node was submitted for histopathology and no lymphoma cells were detected in these samples.

Eleven dogs with lymphoma were client-owned animals presented to the University of Missouri-Columbia Veterinary Medical Teaching Hospital for diagnosis and treatment of suspected lymphoma. Written permission for removal of a lymph node and inclusion in this study was obtained from the owners. One affected peripheral lymph node was obtained from each dog before any chemotherapy was given. Histopathologic examination determined that all of these dogs had Bcell lymphoma. There were seven male and four female dogs. Seven dogs were mixed breed. Of the purebred dogs, there was one each of the following breeds: Newfoundland, Dalmatian, Pembroke Welsh corgi, and Australian shepherd.

Lymph node preparation. All lymph nodes were aseptically removed under general anesthesia. A portion of the node was placed in formalin for the purpose of histopathologic evaluation. The nodes with lymphoma were also submitted for immunophenotyping to determine B-cell or T-cell phenotype. The remainder of the lymph node was prepared for proteomic analysis. The lymph node was trimmed to remove the capsule, connective tissue, and adipose tissue; rinsed with saline; placed in a cryogenic tube; frozen in liquid nitrogen; and stored at $-80^{\circ} \mathrm{C}$ until processed.

Protein solubilization. The protocol for sample solubilization was arrived at empirically to obtain the highest recovery of protein. Sample weight was recorded, and the tissue was ground in dry ice with mortar and pestle. The ground sample and dry ice were placed in a tube and put in $-80^{\circ} \mathrm{C}$ freezer where the dry ice evaporated. Lysis buffer [0.175 $\mathrm{mol} / \mathrm{L}$ Tris-HCl (pH 8.8), 5\% SDS, $15 \%$ glycerol, $0.3 \mathrm{~mol} / \mathrm{L}$ DTT] was added to the frozen samples. Lysis buffer $(5 \mathrm{~mL})$ was added to samples with a weight of $<250 \mathrm{mg}$ (and an additional $1 \mathrm{~mL}$ for each additional $70 \mathrm{mg}$ of tissue). The sample was further solubilized by vortexing, pipetting, and sonication. The insoluble portion was removed by centrifugation in a refrigerated Jouan model CR412 (Jouan, Inc., Winchester, VA) tabletop centrifuge at $1,700 \times \mathrm{g}$ for $10 \mathrm{~min}$ at $4^{\circ} \mathrm{C}$. The supernatant was moved to a glass tube followed by precipitation of the protein with 4 volumes of ice-cold acetone for $1 \mathrm{~h}$ at $-20^{\circ} \mathrm{C}$. The samples were then centrifuged in a Beckman J2-21 centrifuge (Fullerton, CA) at $9,000 \times g$ for $20 \mathrm{~min}$ at $0^{\circ} \mathrm{C}$. The supernatant was discarded and the pellets were rinsed twice in $15 \mathrm{~mL}$ of cold $80 \%$ acetone with mechanical disruption of the pellet by pipetting, vortexing, and sonication. The protein precipitates were then air dried and solubilized in a solution of $8 \mathrm{~mol} / \mathrm{L}$ urea, $2 \mathrm{~mol} / \mathrm{L}$ thiourea, $2 \%$ CHAPS, $0.2 \%$ Triton X-100, $50 \mathrm{mmol} / \mathrm{L}$ DTT, and $0.5 \%$ ampholytes (pH 3-10) at a volume of $6.5 \mu \mathrm{L} / \mathrm{mg}$ of original tissue. The samples were incubated for $1 \mathrm{~h}$ at room temperature, $25 \mathrm{mmol} / \mathrm{L}$ iodoacetamide was added to acetylate all free SH groups, and the samples were centrifuged for $30 \mathrm{~min}$ in a Beckman TL-100 centrifuge at $150,000 \times g$ at $4^{\circ} \mathrm{C}$. The supernatant was removed to clean tubes, and protein concentration of the sample was determined using bicinchoninic acid protein determination assay (Pierce, Rockford, IL).

Protein separation. Two-dimensional SDS-PAGE was used to separate lymph node proteins. Immobilized pH gradient strips $(11 \mathrm{~cm})$ with a pH range of 4 to 7 or 5 to 8 (Proteome Systems Ltd., Boston, MA) were used for the first-dimension separation. The strips were rehydrated with $1.5 \mathrm{mg}$ protein for 20 to $22 \mathrm{~h}$. The proteins were focused for $17 \mathrm{~h}$ on an
Fig. 1. Two-dimensional gel analyses of proteins from normal and lymphoma canine lymph nodes. Lymph nodes were harvested and proteins were solubilized according to the procedure detailed in Materials and Methods. The proteins were separated by first-dimension $\mathrm{pl}$ on either $\mathrm{pH} 4$ to 7 or $\mathrm{pH}$ 5 to 8 immobilized $\mathrm{pH}$ gradient strips followed by second-dimension separation by SDS-PAGE. The figure shows representative gels and molecular weight standards $(M W)$, which were run on each gel. The gels display the high resolution, which was typical of all the gels.

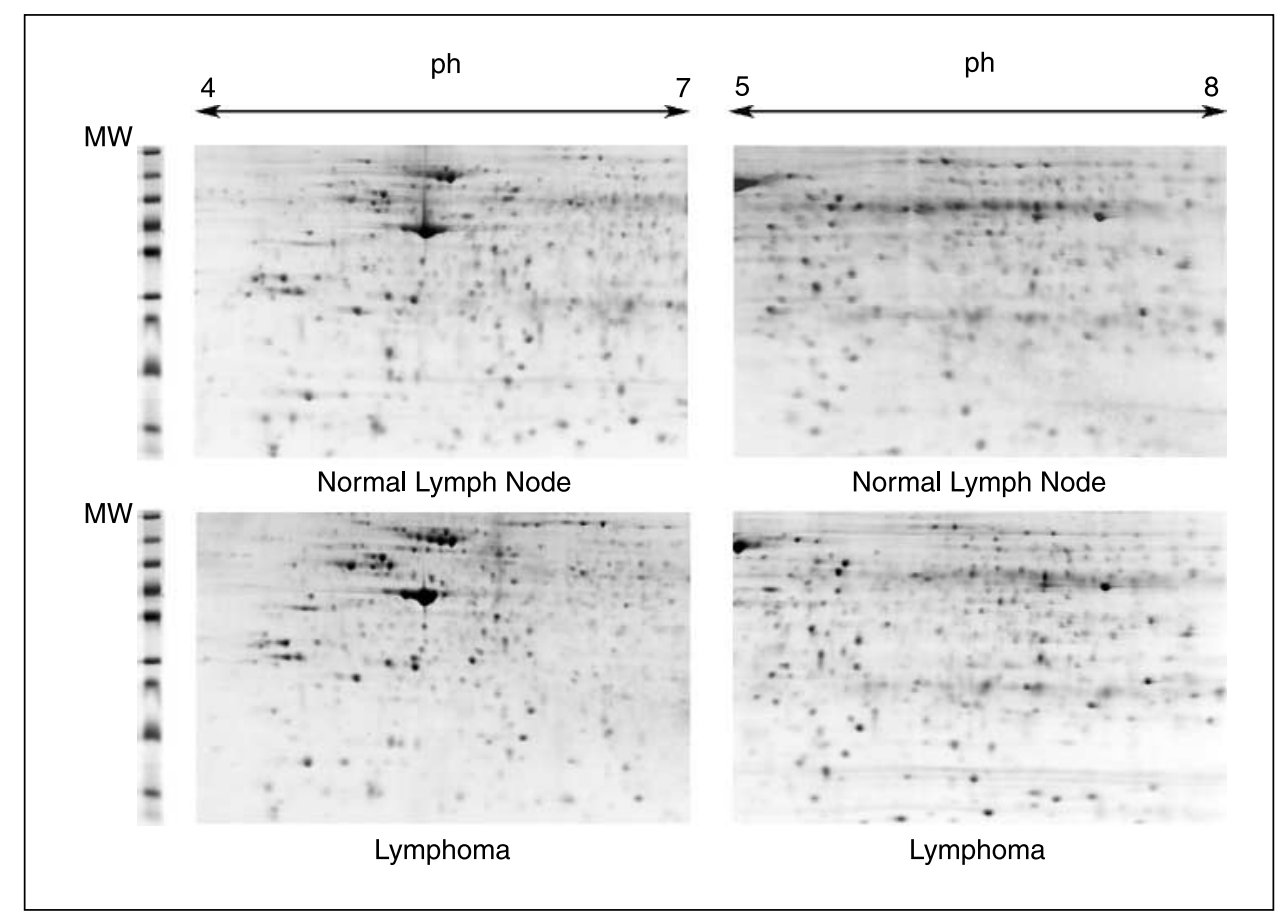


ElectrophoretIQ 2000 system (Proteome Systems). The voltage was steadily increased from 100 to $10,000 \mathrm{~V}$ over $8 \mathrm{~h}$, maintained for an additional $8 \mathrm{~h}$, and then decreased to 2,500 V over $1 \mathrm{~h}$. The immobilized $\mathrm{pH}$ gradient strips were removed and equilibrated with two changes of a solution of $6 \mathrm{~mol} / \mathrm{L}$ urea, $5 \%$ SDS, and $50 \mathrm{mmol} / \mathrm{L}$ Tris-acetate (pH 7.0) for $10 \mathrm{~min}$. The second-dimension separation of proteins was done immediately using precast $8 \%$ to $18 \%$ SDS-PAGE gels (Proteome Systems). Multiple gels were electrophoresed at the same time using the Proteome Systems ElectrophoretIQ 2000 system at $50 \mathrm{~mA}$ per gel for $1.5 \mathrm{~h}$. The gels were then stained for $12 \mathrm{~h}$ with colloidal Coomassie blue (11) and destained in $1 \%$ acetic acid for $2 \mathrm{~h}$.

Gel evaluation. The gels were scanned using a flat bed scanner (Epson Expression 1680, Nagano, Japan). The protein separation patterns were examined visually, and each lymphoma lymph node gel was compared with each normal lymph node gel. The molecular weight markers were from Proteome Systems, and the empirical molecular weights of the separated proteins were estimated to the nearest thousand $\mathrm{kDa}$.

Protein identification. Gel plugs containing spots of interest were excised and destained thrice with $50 \%$ acetonitrile and $50 \mathrm{mmol} / \mathrm{L}$ ammonium bicarbonate. Trypsin digestion was done by incubating the gel plugs with trypsin for $5 \mathrm{~h}$ at $4{ }^{\circ} \mathrm{C}$ followed by replacing the trypsin solution with $30 \mu \mathrm{L}$ of $50 \mathrm{mmol} / \mathrm{L}$ ammonium bicarbonate and continued digestion at $37^{\circ} \mathrm{C}$ for $18 \mathrm{~h}$. Peptides were extracted from gel pieces twice with $60 \%$ acetonitrile and $0.3 \%$ trifluoroacetic acid. Recovered peptides were dried in a centrifugal evaporator and resuspended in $15 \mu \mathrm{L}$ of $1 \%$ formic acid and processed using ZIP tips (Millipore, Billerica, CA). Peptides were eluted from the ZIP tips in $4 \mu \mathrm{L}$ of $70 \%$ acetonitrile and $1 \%$ formic acid, and $1.0 \mu \mathrm{L}$ was spotted onto the matrix-assisted laser desorption/ionization (MALDI) target. Spectra were acquired on an Applied Biosystems 4700 Proteomics Analyzer MALDI tandem time-of-flight mass spectrometer (MS) operated using 4000 Series Explorer software V3.0 in positive ion reflector mode. Instrument calibration in MS mode was achieved using 4700 calibration mixture (Applied Biosystems, Foster City, CA) spotted on six peripheral calibration spots on the MALDI target. Instrument calibration in MS/ MS mode was achieved using the [Glu1]fibrinopeptide B standard $(1,570.7 \mathrm{Da})$ in each of six calibration spots. Sample spectra were acquired in MS mode over a mass range of 800 to 4,000 Da. MS/MS fragmentation spectra of the 10 most abundant peptides (excluding trypsin autolysis peptides) were automatically acquired from each sample. Using default calibration of sample spots, the average mass error (determined by masses of trypsin autolysis ions present in the spectra) ranged from $18.28 \mathrm{ppm}$ in the first sample acquired to 45.35 ppm in the last acquired sample.

Informatics. Searches were conducted with a FASTA-formatted database of DOG gene open reading frames (downloaded from the National Center for Biotechnology Information 03242006 and indexed for use by MASCOT server version 2.1). The canine database was searched using GPS Explorer software V3.0, which is integrated with the MASCOT search engine. A "combined MS + MS/MS" search was conducted that includes a peptide mass fingerprinting approach to protein identification supplemented with MS/MS ion searches of those peptides acquired from the sample. Search variables for DOG FASTA database: monoisotopic peaks only, filtering mass range of 800 to 4,000 $\mathrm{Da}$, minimum s/n ratio of 10, "common" trypsin autolysis ions within a mass tolerance of $75 \mathrm{ppm}$ were removed from the spectra before the database search, density filter of 50 peaks per $200 \mathrm{Da}$, and maximum of 100 peaks per spectrum. Database search criteria included one allowed miscleavage, carbamidomethyl fixed modification, methionine oxidation and deamidation of $\mathrm{N}$ and $\mathrm{Q}$, precursor mass tolerance of $75 \mathrm{ppm}$, MS/MS fragment tolerance of $0.05 \mathrm{Da}$, minimum two identified peptides, and minimum ion score confidence interval of $85 \%$.

Statistical methods. Fisher's exact test was used for determining the significance of the differential expression of a protein in the normal and lymphoma samples. Statistical calculations were done with the computer-based software SigmaStat for Windows version 3.10 (Systat Software, Inc., Richmond, CA). Significance was set at $P<0.05$.

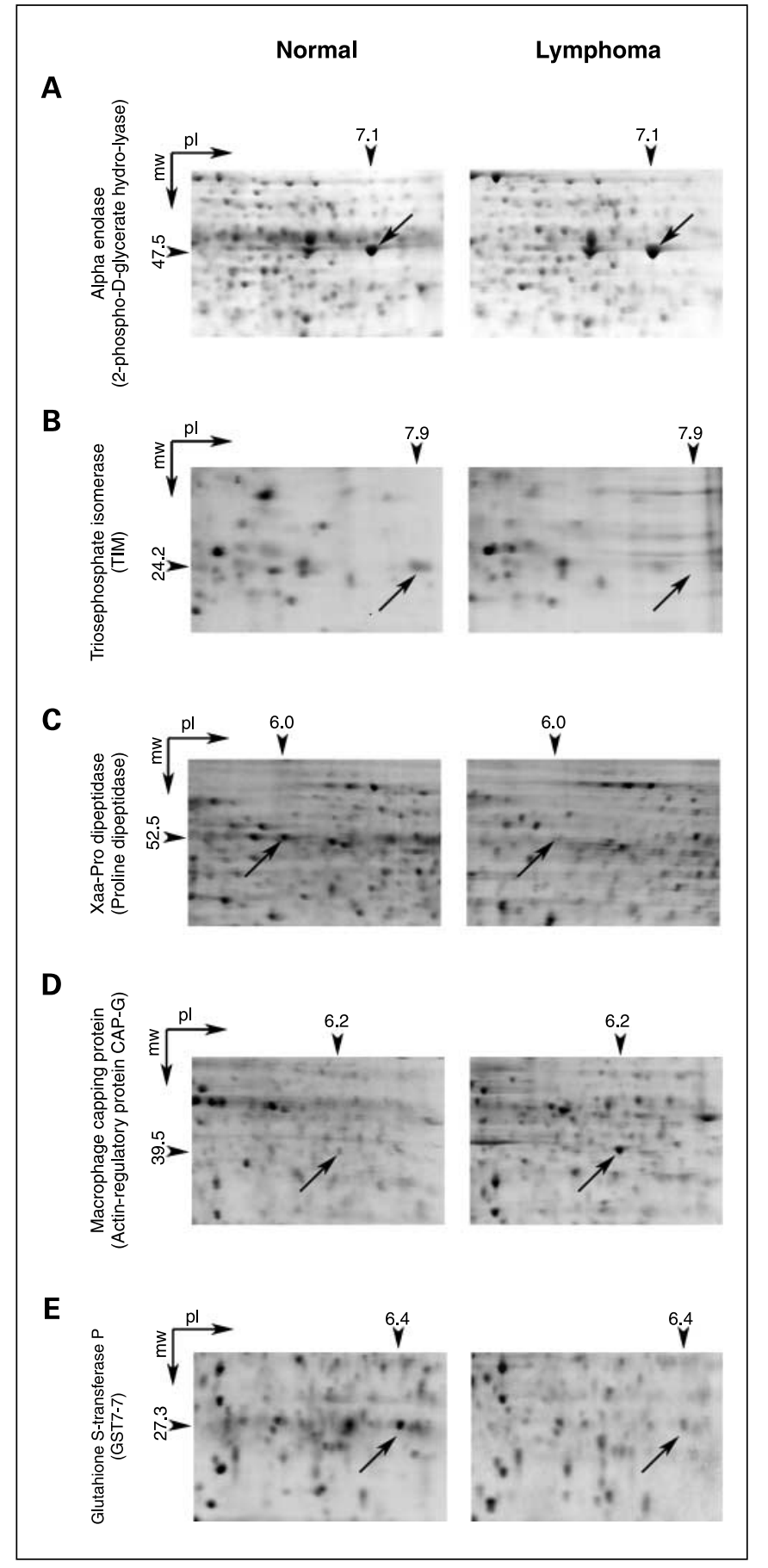

Fig. 2. Differential expression of proteins between normal (noncancerous) and lymphoma lymph nodes. Comparisons of representative gels showing the differential expression of proteins identified in this study. Black arrow, spot presence (or absence). Vertical arrowhead, $\mathrm{pH}$ or pl. Horizontal arrowhead, molecular weight $(m w)$ of each spot. $(A)$ Equal expression of a protein is depicted. In $(C),(D)$, and $(E)$, there is a differential expression of the protein, whereas in $(B)$ there is a complete absence in the lymphoma sample.

\section{Results}

Participating animals. The participating animals were first screened for the presence and type of the disease. None of the nondiseased dog samples had evidence of lymphoma. All the lymphoma samples were found to be B-cell phenotype based on 
CD79-positive reaction. The lymphomas were classified using the NIH working formulation and composed of diffuse small cleaved cell lymphoma, diffuse large cleaved cell lymphoma, diffuse large noncleaved cell lymphoma, and diffuse mixed cell lymphoma (1). The limited numbers of each tumor type prevented any meaningful correlation with the proteomic data.

Sample preparation and gel evaluation. Standard, commercially available lysis buffers resulted in gels of poor quality, and the sample solubilization procedure described in Materials and Methods was developed. The proteins were then separated by two-dimensional PAGE using a pH range of either 5 to 8 or 4 to 7 for the first dimension and $8 \%$ to $18 \%$ SDS-PAGE gels for the second dimension. This method of sample preparation resulted in gels that had reproducibly high resolution as is shown in Fig. 1.

The gels were scanned as described and visually examined. Each lymphoma lymph node gel was compared with each normal lymph node gel. Any differences in protein expression between the compared gels were noted. Examples of four of these differentially expressed spots are depicted in Fig. 2. Twenty-one protein spots were identified as having differences in expression between nonlymphomas and lymphomas. In some cases, the proteins showed higher expression in the lymphoma lymph nodes compared with nonlymphoma lymph nodes, and in other cases, the opposite was observed. Seventeen of these differentially expressed spots were seen on the pH 5 to 8 gels (Table 1) and four protein spots were seen on the $\mathrm{pH} 4$ to 7 gels (Table 2). Several randomly selected samples representing the differentially regulated proteins were removed from the gels for protein identification by MALDI time-of-flight MS (noted with an asterisk in Tables 1 and 2). The distribution of the protein spots in the normal versus lymphoma samples is shown with respect to either the total number of samples or the number of samples that had that spot (Table 3). The latter ratio is important because it highlights the bias, and thus the predictive value, of the protein for either the normal or lymphoma samples.

Protein identification. To test the reproducibility of the approach, we analyzed two proteins: one that appeared in all the normal and lymphoma pH 5 to 8 gels and the other appeared on all the $\mathrm{pH} 4$ to 7 gels. From the $\mathrm{pH} 5$ to 8 gels, the spots had an observed molecular weight of 45,000 and an isoelectric focusing (pI) of 7.3. Seven spots (three from normal lymph node gels and four from lymphoma) were picked for analysis. Six of the seven were identified as $\alpha$-enolase, an

Table 1. Summary of two-dimensional electrophoretic analysis of proteins from noncancerous and lymphoma lymph nodes

\begin{tabular}{|c|c|c|c|c|c|c|c|c|c|c|c|c|c|c|c|c|c|c|}
\hline \multirow{2}{*}{$\begin{array}{l}\text { Sample/ } \\
\text { gel }\end{array}$} & \multicolumn{18}{|c|}{ Protein spot no. } \\
\hline & 1 & 2 & 3 & 4 & 5 & 6 & 7 & 8 & 9 & 10 & 11 & 12 & 13 & 14 & 15 & 16 & 17 & C \\
\hline $\mathrm{N}$ & $*$ & $*$ & $*$ & & & & & $*$ & & & & & & & & & & * \\
\hline $\mathrm{N}$ & $*$ & $*$ & & & & & & & $*$ & $*$ & & & & & & $*$ & & \\
\hline $\mathrm{N}$ & & & & $*$ & & & & $*$ & & & & & & & & & & \\
\hline $\mathrm{N}$ & & & & & & & & & & $*$ & & & & * & & & & $*$ \\
\hline \multicolumn{19}{|l|}{$\mathrm{N}$} \\
\hline $\mathrm{N}$ & $*$ & $*$ & & & & & & $*$ & & & & & & & & $*$ & & \\
\hline $\mathrm{N}$ & & & & & & & $*$ & & & & & & & & & & & \\
\hline $\mathrm{N}$ & & & & & $*$ & $*$ & & & $*$ & & & & & & & & & \\
\hline $\mathrm{N}$ & & & $*$ & $*$ & & & $*$ & & & $*$ & & & & & & & & \\
\hline $\mathrm{N}$ & & & & & & & $*$ & & & $*$ & & & & & & & & \\
\hline $\mathrm{N}$ & $*$ & $*$ & $*$ & & & & $*$ & & & & & & & & & & & \\
\hline $\mathrm{N}$ & & & & & $*$ & $*$ & & & & & & & & 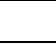 & & & & $*$ \\
\hline \multicolumn{19}{|l|}{$\mathrm{N}$} \\
\hline & & & & & & & & & & & & & & & & & & \\
\hline $\mathrm{L}$ & & & & & & & & & & & & & & $*$ & $*$ & & & $*$ \\
\hline$L$ & & & & & & & & & $*$ & & & & $*$ & * & $*$ & & & \\
\hline $\mathrm{L}$ & & & & & & & & & & & & & $*$ & & & & & \\
\hline $\mathrm{L}$ & & & & & & & & & & & & & & & $*$ & & & \\
\hline $\mathrm{L}$ & $*$ & & & & $*$ & $*$ & & & & & & & & & & & & $*$ \\
\hline$L$ & $*$ & $*$ & & $*$ & & & & & & & & & $*$ & & & & & \\
\hline$L$ & & & & & & & & & & & $*$ & $*$ & $*$ & * & & & $*$ & \\
\hline $\mathrm{L}$ & & & & & & $*$ & & & $*$ & & & & $*$ & $*$ & & & & \\
\hline $\mathrm{L}$ & & & & & & $*$ & & & & & & & & & & $*$ & $*$ & $*$ \\
\hline $\mathrm{L}$ & & & & & & & & $*$ & & & & & & & & & & \\
\hline $\mathrm{L}$ & $*$ & $*$ & & & & & & & & & & & & & & & & $*$ \\
\hline
\end{tabular}

NOTE: $\mathrm{pI}$ at $\mathrm{pH} 5$ to 8 . Shaded boxes indicate the presence of a protein spot. *, spot excised for MALDI time-of-flight analysis. Abbreviations: N, noncancerous; L, lymphoma; C, control. 
abundant cytosolic protein with a predicted molecular weight of 49,500 (Fig. 2A and "control" lane in Table 1). From the pH 4 to 7 gels, three spots (two normal and one lymphoma) were picked for analysis with a molecular weight of 16,000 and a pI of 6.7 (Table 2, control lane). Two of the three were identified as superoxide dismutase, whereas the other spot gave no identification. Overall, this underscored the reproducibility of the gels and suggested that the approach of spot evaluation and identification had worked well.

Of the 21 proteins that were expressed differentially between cancerous and noncancerous lymph nodes, 4 gave consistent identification of the spots picked for analysis (Table 4). No consensus of identification was found with the others, which is most likely due to low protein levels and/or overlapping of multiple proteins in the gel.

(a) A protein with an observed molecular weight of $24 \mathrm{kDa}$ and a pI of 7.9 was present in 9 of 13 gels from normal lymph nodes but only in 1 of 11 gels of the lymphoma samples (Fig. 2B; Table 1, spot no. 4). The difference was significant $(P=0.005)$. In three of four representative analyzed spots, it was identified as triosephosphate isomerase, a glycolytic enzyme. It functions in catalyzing the interconversion of glyceraldehyde-3-phosphate and dihydroxyacetone phosphate. Triosephosphate isomerase is necessary for efficient energy production, is important in several metabolic pathways, and is present in the cytoplasm of all tissues (12). An inherited deficiency occurs in humans and causes a rise in dihydroxyacetone phosphate. Clinical signs are hemolytic anemia, early death, and neurodegeneration (13).

(b) A protein with observed molecular weight of $55 \mathrm{kDa}$ and pI of 6.1 was found in 8 of 13 of the normal samples and in none of the lymphoma samples (Fig. 2C; Table 1, spot no. 7). The difference was significant $(P=0.006)$. Four representative spots were analyzed, and three resulted in the identification of Xaa-Pro dipeptidase (prolidase). Prolidase is a 492-amino acid (54.5 kDa) manganese metalloenzyme, which catalyzes the release of any $\mathrm{NH}_{2}$-terminal amino acid adjacent to a proline residue. The enzyme splits dipeptides with a prolyl residue in the COOH-terminal position. Bacterial aminopeptidases P II (gene pepP) and proline dipeptidase (gene pepQ), yeast hypothetical proteins YER078c and YFR006w, Mycobacterium tuberculosis hypothetical protein MtCY49.29c, and human proline dipeptidase (gene PEPD) are evolutionary related. Proline peptidase plays an important role in collagen metabolism because of the high level of iminoacids in collagen. The released proline is used for the production of collagen (14). Prolidase has high enzyme activity in the intestinal mucosa, kidney, and erythrocytes. Liver, brain, heart, uterus, thymus, leukocytes, and skin fibroblasts also contain prolidase (14).

(c) A protein with an observed molecular weight of $36 \mathrm{kDa}$ and a pI of 6.4 was found in 6 of 11 of the lymphoma samples and in 3 of 13 normal gels (Fig. 2D; Table 1, spot no. 16). The difference was not significant $(P=0.206)$. In three of three representative analyzed spots, it was identified as macrophage capping protein, a 348-amino acid (38.5 kDa) calciumsensitive protein. Interestingly, a second group of protein spots at molecular weight of $29 \mathrm{kDa}$ and a pI of 6.7 (Table 1, spot no. 13), which also was primarily lymphoma associated ( 5 of the 11 lymphoma gels and 0 of 13 normal gels), was also identified as macrophage capping protein in three of the five spots analyzed. The difference was significant $(P=0.011)$. This group
Table 2. Summary of two-dimensional electrophoretic analysis of proteins from noncancerous and lymphoma lymph nodes

\begin{tabular}{|c|c|c|c|c|c|}
\hline Sample & 18 & 19 & 20 & 21 & C \\
\hline \multicolumn{6}{|l|}{$\mathrm{N}$} \\
\hline \multicolumn{6}{|l|}{$\mathrm{N}$} \\
\hline \multicolumn{6}{|l|}{$\mathrm{N}$} \\
\hline \multicolumn{6}{|l|}{$\mathrm{N}$} \\
\hline $\mathrm{N}$ & & & $*$ & & $*$ \\
\hline $\mathrm{N}$ & $*$ & & & $*$ & \\
\hline \multicolumn{6}{|l|}{$\mathrm{N}$} \\
\hline $\mathrm{N}$ & & $*$ & & & \\
\hline $\mathrm{N}$ & & $*$ & & & $*$ \\
\hline $\mathrm{N}$ & $*$ & $*$ & & $*$ & \\
\hline \multicolumn{6}{|l|}{$\mathrm{N}$} \\
\hline \multicolumn{6}{|l|}{$\mathrm{N}$} \\
\hline & & & & & \\
\hline \multicolumn{6}{|l|}{$\mathrm{L}$} \\
\hline \multicolumn{6}{|l|}{$L$} \\
\hline $\mathrm{L}$ & $*$ & & & $*$ & \\
\hline$L$ & & & $*$ & & \\
\hline $\mathrm{L}$ & & & & $*$ & \\
\hline$L$ & & & & $*$ & \\
\hline$L$ & & $*$ & & & $*$ \\
\hline \multicolumn{6}{|l|}{$L$} \\
\hline$L$ & & * & & & \\
\hline$L$ & $*$ & & * & & \\
\hline
\end{tabular}

NOTE: $\mathrm{pI}$ at $\mathrm{pH} 4$ to 7 . Shaded boxes indicate the presence of a protein spot. *, spot excised for MALDI time-of-flight analysis.

of spots could possibly represent a processing product of the protein, but more extensive analysis is needed to answer this question. Macrophage capping protein, along with gelsolin, villin, adseverin, advillin, and supervillin, is a member of the gelsolin protein family (15). These proteins cap the barbed ends of actin filaments that are necessary for regulating actinbased motility in nonmuscle cells. Macrophage capping protein was first isolated from alveolar macrophages (16). The levels are highest in macrophages where it is a major stimulator of macrophage phagocytosis (17). Detection of macrophage capping protein in other tissues is variable, with one report suggesting presence in lung, kidney, and smaller amounts in the heart, whereas another study found macrophage capping protein in the spleen $(18,19)$. A third study suggests more widespread presence, including skeletal muscle, stomach, spleen, kidney, heart, lung, intestine, and uterus (20).

(d) A protein spot with an observed molecular weight of 24 $\mathrm{kDa}$ and a pI of 7.0 was observed in 11 of 13 normal lymph nodes and in only 3 of 11 gels of lymphoma samples (Fig. 2E; Table 1 , spot no. 2). The difference was significant $(P=0.011)$. In three of four representative spots analyzed from the normal gels, it was identified as glutathione $S$-transferase-P (GST-P; GST7-7). GST-P is one of the five soluble cytosolic GST isoenzymes that are each a distinct gene product. The enzymes transfer reduced glutathione to a broad range of genotoxins to 
detoxify them and facilitate their removal from cells. These enzymes are widely expressed in tissues, and their expression is up-regulated on cell exposure to genotoxins. The enzymes are generally believed to protect cells from carcinogens (21).

\section{Discussion}

The goals of cancer research include a better understanding of the development of cancer cells and their interactions with normal cells. To this end, it has been productive to identify cellular and biochemical differences between normal and tumor cells. Modern system approaches to this problem include using microarray analysis to determine differences in mRNA levels and gene methylation patterns between normal and cancer cells or proteomic analysis to directly detect changes in protein expression and/or posttranslational modifications (e.g., phosphorylation, glycosylation, lipidation, and peptide cleavage) in the cancer cell $(22,23)$. We applied this latter approach to study the differences between the proteomes of cancerous and noncancerous lymph nodes of dogs. Canine lymphoma is an attractive translational model for human cancer because it is a common nonviral-associated spontaneous neoplasm in dogs and is similar to human non-Hodgkin's lymphoma. Canine lymphoma is treated with the same drugs as human lymphoma, most commonly vincristine, cyclophosphamide, L-asparaginase, doxorubicin, and prednisone (9), and taken together with the availability of samples, these considerations make the dog an excellent candidate for proteomic-based research on cancer.

In this study, significant differences in protein expression were detected between the lymph nodes of normal dogs and those with B-cell lymphoma. In some instances, there was a differential up-regulation or down-regulation. In many cases, a protein was not limited exclusively to either normal of cancerous lymph nodes. We believe that our experimental approach facilitated these findings. Previous strategies have often used a reference gel that is composed of all the spots present on gels from multiple samples of normal cells or tissues. The reference gel was then used to compare spots present on the gels from the diseased tissue. Thus, in order for a particular protein in a diseased sample to be recognized as uniquely present or absent, it could not have been present on any of the normal gels. However, there are many genetic, physiologic, and environmental differences between animals that complicate this approach. As cancer progresses, the protein profile will gradually change, and each individual can display a different pattern of change, with the proteome of some nondisease-appearing animals containing the proteins of diseased individuals and vice versa. For lymph nodes, it is reasonable to assume that the protein profile of a particular node is directly dependent on what is happening in the tissues that drain to that lymph node, and as such, the lymph nodes from different animals could have different proteomes. Based on these considerations, our approach was to systematically compare each lymphoma sample to each nondiseased sample and then record the protein spots that differ in each set, assuming that there is not an absolute difference between the protein profiles of normal and diseased tissue. Indeed, a similar result was seen in previous proteomic analyses of other cancers $(24,25)$. Overall, this supports the idea that multiple markers will be needed for accurate cancer diagnosis, and ultimately, markers discovered in different studies will probably be used together for diagnosis and staging. The current study in dogs identified four candidates as markers for lymphoma.

Prolidase was found to be expressed in some normal but not lymphoma samples. As an iminopeptidase enzyme, prolidase is necessary for protein catabolism or processing. An inherited

\begin{tabular}{|c|c|c|c|c|c|}
\hline $\begin{array}{l}\text { Protein } \\
\text { spot no. }\end{array}$ & $\begin{array}{l}\text { Samples with } \\
\text { protein spot } \\
\text { present (\%) }\end{array}$ & $\begin{array}{l}\text { Noncancerous } \\
\text { samples with } \\
\text { protein spot present } \\
\text { (\% of total samples) }\end{array}$ & $\begin{array}{l}\text { Lymphoma } \\
\text { samples with } \\
\text { protein spot present } \\
\text { (\% of total samples) }\end{array}$ & $\begin{array}{l}\text { Noncancerous } \\
\text { samples in } \\
\text { total positive } \\
\text { samples }(\%)\end{array}$ & $\begin{array}{l}\text { Lymphoma } \\
\text { samples in } \\
\text { total positive } \\
\text { samples (\%) }\end{array}$ \\
\hline 1 & 63 & 50 & 13 & 80 & 20 \\
\hline 2 & 63 & 50 & 13 & 80 & 20 \\
\hline 3 & 42 & 42 & 0 & 100 & 0 \\
\hline 4 & 42 & 38 & 4 & 90 & 10 \\
\hline 5 & 42 & 38 & 4 & 90 & 10 \\
\hline 6 & 59 & 38 & 21 & 64 & 36 \\
\hline 7 & 33 & 33 & 0 & 100 & 0 \\
\hline 8 & 33 & 29 & 4 & 88 & 13 \\
\hline 9 & 50 & 29 & 21 & 58 & 42 \\
\hline 10 & 25 & 25 & 0 & 100 & 0 \\
\hline 11 & 4 & 0 & 4 & 0 & 100 \\
\hline 12 & 13 & 0 & 13 & 0 & 100 \\
\hline 13 & 21 & 0 & 21 & 0 & 100 \\
\hline 14 & 25 & 4 & 21 & 17 & 83 \\
\hline 15 & 25 & 0 & 25 & 0 & 100 \\
\hline 16 & 38 & 13 & 25 & 33 & 67 \\
\hline 17 & 46 & 17 & 29 & 36 & 64 \\
\hline 18 & 73 & 50 & 23 & 69 & 31 \\
\hline 19 & 64 & 41 & 23 & 64 & 36 \\
\hline 20 & 73 & 41 & 32 & 56 & 44 \\
\hline 21 & 81 & 36 & 45 & 44 & 56 \\
\hline
\end{tabular}

NOTE: Isoelectric focusing $\mathrm{pH}$ 5-8 (spots 1-17) and $\mathrm{pH} 4-7$ (spots 18-21). 


\begin{tabular}{|c|c|c|c|c|c|c|c|c|}
\hline Protein name & Synonyms & $\begin{array}{l}\text { Gene } \\
\text { name }\end{array}$ & $\begin{array}{l}\text { Accession } \\
\text { no. }\end{array}$ & $\begin{array}{l}\text { Molecular } \\
\text { weight } \\
\text { (kDa) }\end{array}$ & $\begin{array}{l}\% \\
\text { Coverage }\end{array}$ & $\begin{array}{l}\text { Mowse } \\
\text { score }\end{array}$ & $\begin{array}{l}\text { Normal } \\
\text { samples }\end{array}$ & $\begin{array}{l}\text { Lymphoma } \\
\text { samples }\end{array}$ \\
\hline $\begin{array}{l}\text { Trioseposphate } \\
\text { isomerase }\end{array}$ & $\begin{array}{l}\text { Phosphotriose } \\
\text { isomerase; triose } \\
\text { phosphoisomerase; } \\
\text { triosephosphate } \\
\text { isomerase; } \\
\text { triosephosphate } \\
\text { mutase }\end{array}$ & TIM & P54714 & 26.7 & 72 & 74 & 9 of 13 & 1 of 11 \\
\hline $\begin{array}{l}\text { Xaa-Pro } \\
\text { dipeptidase }\end{array}$ & $\begin{array}{l}\gamma \text {-Peptidase; } \\
\text { iminopeptidase; } \\
\text { peptidase } D ; \text { proline } \\
\text { peptidase; X-Pro } \\
\text { dipeptidase; } \\
\text { EC } 3.4 .13 .9\end{array}$ & PEPD human & P12955 & 54.5 & 32 & 67 & 8 of 13 & 0 of 11 \\
\hline $\begin{array}{l}\text { Macrophage } \\
\text { capping } \\
\text { protein }\end{array}$ & $\begin{array}{l}\text { Actin-regulatory } \\
\text { protein CAPG }\end{array}$ & $\begin{array}{l}\text { LOC483082; } \\
\text { CAPG human; } \\
\text { MCP }\end{array}$ & P40121 & 38.5 & 49 & 121 & $\begin{array}{l}3 \text { of } 13 \\
\quad(0 \text { of } 13 \text { in } \\
\text { second group) }\end{array}$ & $\begin{array}{l}6 \text { of } 11 \\
\text { ( } 5 \text { of } 11 \text { in } \\
\text { second group) }\end{array}$ \\
\hline GST-P & GST7-7; EC 2.5.1.18 & GST7-7 & XP_532423 & 23.4 & 30 & 66 & 11 of 13 & 3 of 11 \\
\hline
\end{tabular}

autosomal recessive deficiency of prolidase enzyme activity has been reported in humans and presents with variable symptoms, such as chronic recurrent infections, splenomegaly, skin lesions, and mental retardation (14). In contrast, decreased prolidase expression, without a general decrease, has been found in diseased pancreatic tissue. A 2-fold decrease in prolidase activity compared with normal tissue was seen in pancreatitis, and a 10-fold decrease was found in pancreatic cancer tissue (26). Prolidase activity has also been shown to be reduced in human MCF-7 breast cancer cells when compared with normal human fibroblasts (27). The significance of reduced prolidase in cancerous tissue is unknown (27). The lack of prolidase in the lymphoma samples in this study agrees with previous study of cancer tissues. It should be stressed that our results do not imply that it was totally absent but rather reduced to below the level of detection.

Macrophage capping protein was found primarily in lymphoma samples. It is a member of the gelsolin family, which are proteins that bind actin. Included in this family are gelsolin, villin, adseverin, macrophage capping protein, advillin, and supervillin. Unlike other members, macrophage capping protein binds but does not sever actin and the binding is reversible based on $\mathrm{Ca}^{2+}$ levels (low levels reduce binding; ref. 15). Macrophage capping protein is more abundant than gelsolin in macrophages (15), and overexpression increases macrophage phagocytic activity (28). Macrophage capping protein null mice appear grossly normal and have normal numbers of neutrophils, lymphocytes, and mononuclear cells. Macrophage phagocytosis is decreased to about half that of normal mice. However, despite this understanding of macrophage capping protein function, this study suggests its first association with cancer. The increase of macrophage capping protein may be a result of an inflammatory reaction occurring in the cancerous lymph nodes, quite possibly a direct reaction to the neoplastic cells.

Our results, finding an absence of triosephosphate isomerase in most lymphoma cases, are in contrast with previous findings of other investigators. Two-dimensional electrophoretic analysis of lung adenocarcinoma revealed an increase of triosephosphate isomerase in $60 \%$ of adenocarcinomas compared with uninvolved lung (29). Similarly, increased expression of triosephosphate isomerase was found in lung squamous cell carcinomas (30). Triosephosphate isomerase has also been found to be increased in urinary cancers. Renal cell carcinoma samples when compared with normal kidney cortex had increased expression in all six samples tested (31). Possibly, the down-regulation of triosephosphate isomerase in the lymphoma samples represents an underlying cell type specificity, but overall, it seems that misregulation of triosephosphate isomerase is a common feature of cancer. Additional work will be required to fully understand all these data and to elucidate the mechanistic relationship between this enzyme and the various forms of cancer.

There is a large literature on the roles of GST with respect to cancer, and there is not a clear pattern (32). In addition to the idea that the detoxifying activity of GST protects cells from carcinogens, there are also reports that increases in GST are correlated with increased resistance to chemotherapeutic drugs and poor prognosis (33). Several studies clearly show an inverse correlation between GST-P expression and cancer. In studies of esophageal adenocarcinoma and ovarian cancer, the tumor tissue showed lower GST-P levels in tumor tissue than in the surrounding normal tissue $(34,35)$. The current studies on canine lymphoma agree in that GST-P was observed more frequently in the normal lymph nodes. This general pattern supports the idea that loss of GST activity is associated with tumor development.

In some cases, like with the GST and with the macrophage capping protein, we identified protein spots that correspond to these proteins but had lower than expected molecular weight. Although it is entirely possible that these represent proteolytic cleavage, it is important to mention that there is an increasing literature on alternative splicing and its role in regulation of cellular function (36). It will be interesting to analyze these genes for possible alternative splice variants and to ascertain whether these have a regulatory role in the onset or propagation of lymphoma.

A possible drawback to using whole lymph node tissue is its cellular heterogeneity (37). Tissues are composed of not only the functional immune cells but also supporting structures, 
such as connective tissue, blood vessels and blood cells, and fat. Tumors are also heterogeneous and contain mixtures of normal, transformed, and malignant cells, although in lymphomas nearly the entire lymph node is composed of malignant cells. Despite these concerns, using lymph node tissue allowed us to directly examine normal and tumor tissue without any cell culture or cell fractionation and resulted in the identification of the differentially expressed proteins.

Two-dimensional gel electrophoresis is widely available for protein separation in proteomic studies and allows broad proteomic analyses to be routinely done. The technique is somewhat limited by sensitivity (10), but as can be seen in Figs. 1 and 2, a large number of proteins can be reproducibly separated and displayed. This approach allowed us to compare, for the first time, the proteomes of lymph nodes from normal dogs and dogs with lymphoma. The discovery that GST, macrophage capping protein, triosephosphate isomerase, and prolidase were differentially expressed between the normal and cancerous lymph nodes strongly supports the use of dogs as an effective model for the study of malignancy. Other proteomic studies of cultured cancer cells and tissues also have frequently identified a relatively small set of differentially regulated proteins, which may reflect the unique set of factors (e.g., sample type and methods of protein separation and identification) involved in the studies $(38,39)$. Thus, additional proteomic analyses of canine tumors using other techniques are expected to provide the identification of additional interesting markers that are expected to be of value in both veterinary and human medicine.

This study represents an initial and necessary step needed to identify markers that are differentially expressed between normal and cancerous lymph nodes, which ultimately can be used for diagnosis, staging, and monitoring of therapy. The dog offered experimental advantages and should continue to be useful in identifying more markers. Nevertheless, validation of the identified protein markers by other techniques (e.g., ELISAbased methods) in larger numbers of samples will be needed. In addition, an examination of these markers in human lymphoma samples will be an important goal. In this way, these and other markers can be evaluated for their full potential for diagnosis compared with currently used methods of histotyping. There is the potential for these markers, once validated, to be routinely measured in both veterinary and human clinical settings.

\section{References}

1. Vail DM, MacEwen EG. Spontaneously occurring tumors of companion animals as models for human cancer. Cancer Invest 2000;18:781 -92.

2. Jonasdottir TJ, Mellersh CS, Moe L, et al. Genetic mapping of a naturally occurring hereditary renal cancer syndrome in dogs. Proc Natl Acad Sci U S A 2000;97:4132-7.

3. Lingaas F, Comstock KE, Kirkness EF, et al. A mutation in the canine BHD gene is associated with hereditary multifocal renal cystadenocarcinoma and nodular dermatofibrosis in the German Shepherd dog. Hum Mol Genet 2003;12:3043-53.

4. Nickerson ML, Warren MB, Toro JR, et al. Mutations in a novel gene lead to kidney tumors, lung wall defects, and benign tumors of the hair follicle in patients with the Birt-Hogg-Dube syndrome. Cancer Cell 2002;2: $157-64$.

5. Lindblad-Toh K, Wade CM, Mikkelsen TS, et al. Genome sequence, comparative analysis and haplotype structure of the domestic dog. Nature 2005; 438:803-19

6. MacEwen EG. Spontaneous tumors in dogs and cats: models for the study of cancer biology and treatment. Cancer Metastasis Rev 1990;9:125-36.

7. Morton LM, Wang SS, Devesa SS, et al. Lymphoma incidence patterns by WHO subtype in the United States, 1992-2001. Blood 2006;107:265-76.

8. Greenlee PG, Filippa DA, Quimby FW, et al. Lymphomas in dogs. A morphologic, immunologic, and clinical study. Cancer 1990;66:480-90.

9. Vail DM, MacEwen EG, Young KM. Canine lymphoma and lymphoid leukemias. In: Withrow SJ, MacEwen EG, editors. Small animal clinical oncology. Philadelphia:W.B. Saunders; 2001. p. 558-84.

10. Righetti PG, Castagna A, Antonucci F, et al. Proteome analysis in the clinical chemistry laboratory: myth or reality? Clin Chim Acta 2005;357:123-39.

11. Neuhoff V, Arold N, Taube D, Ehrhardt W. Improved staining of proteins in polyacrylamide gels including isoelectric focusing gels with clear background at nanogram sensitivity using Coomassie Brilliant Blue G-250 and R-250. Electrophoresis 1988;9:255-62.

12. Montgomerie JZ, Gracy RW, Holshuh $\mathrm{HJ}$, et al. The $28 \mathrm{~K}$ protein in urinary bladder, squamous metaplasia and urine is triosephosphate isomerase. Clin Biochem 1997;30:613-8.

13. Olah J, Orosz F, Puskas LG, et al. Triosephosphate isomerase deficiency: consequences of an inherited mutation at mRNA, protein and metabolic levels. Biochem J 2005;392:675-83.

14. Kurien BT, Patel NC, Porter AC, et al. Prolidase deficiency and the biochemical assays used in its diagnosis. Anal Biochem 2006;349:165-75.

15. Pellieux C, Desgeorges A, Pigeon CH, et al. Cap G, a gelsolin family protein modulating protective effects of unidirectional shear stress. J Biol Chem 2003;278: 29136-44.

16. Southwick FS, DiNubile MJ. Rabbit alveolar macrophages contain a $\mathrm{Ca}^{2+}$-sensitive, 41,000 -dalton protein which reversibly blocks the "barbed" ends of actin filaments but does not sever them. J Biol Chem 1986;261:14191-5.

17. Witke W, Li W, Kwiatkowski DJ, Southwick FS. Comparisons of $\mathrm{CapG}$ and gelsolin-null macrophages: demonstration of a unique role for CapG in receptormediated ruffling, phagocytosis, and vesicle rocketing. J Cell Biol 2001;154:775-84

18. Prendergast GC, Ziff EB. Mbh 1: a novel gelsolin/ severin-related protein which binds actin in vitro and exhibits nuclear localization in vivo. EMBO J 1991;10: $757-66$.

19. Dabiri GA, Young CL, Rosenbloom J, Southwick FS. Molecular cloning of human macrophage capping protein cDNA. A unique member of the gelsolin/villin family expressed primarily in macrophages. J Biol Chem 1992;267:16545-52.

20. Yu F, Johnston, PA, Sudhof TC, Yin HL. gCap39, a calcium ion- and polyphosphoinositide-regulated actin capping protein. Science 1990;250:1413-5.

21. Hayes JD, Pulford DJ. The glutathione S-transferase supergene family: regulation of GST and the contribution of the isoenzymes to cancer chemoprotection and drug resistance. Crit Rev Biochem Mol Biol 1995; 30:445-600.

22. Banks RE, Dunn MJ, Hochstrasser DF, et al. Proteomics: new perspectives, new biomedical opportunities. Lancet 2000;356:1749-56.

23. Rosenblatt KP, Bryant-Greenwood P, Killian JK, et al. Serum proteomics in cancer diagnosis and management. Annu Rev Med 2004;55:97-112.

24. Petricoin EF, Ardekani AM, Hitt BA, et al. Use of proteomic patterns in serum to identify ovarian cancer. Lancet 2002;359:572-7.

25. Alexander H, Stegner AL, Wagner-Mann C, Du Bois GC, Alexander S, Sauter ER. Proteomic analysis to identify breast cancer biomarkers in nipple aspirate fluid. Clin Cancer Res 2004;10:7500-10.
26. Palka J, Surazynski A, Karna E, et al. Prolidase activity disregulation in chronic pancreatitis and pancreatic cancer. Hepatogastroenterology 2002;49: $1699-703$.

27. Palka JA, Phang JM. Prolidase in human breast cancer MCF-7 cells. Cancer Lett 1998;127:63-70.

28. Sun HQ, Kwiatkowska K, Wooten DC, Yin HL. Effects of CapG overexpression on agonist-induced motility and second messenger generation. J Cell Biol 1995; 129:147-56.

29. Chen G, Gharib TG, Huang CC, et al. Proteomic analysis of lung adenocarcinoma: identification of a highly expressed set of proteins in tumors. Clin Cancer Res 2002;8:2298-305.

30. Li C, Xiao Z, Chen Z, et al. Proteome analysis of human lung squamous carcinoma. Proteomics 2006;6: 547-58.

31. Unwin RD, Craven RA, Harnden P, et al. Proteomic changes in renal cancer and co-ordinate demonstration of both the glycolytic and mitochondrial aspects of the Warburg effect. Proteomics 2003;3:1620-32.

32. Aliya S, Reddanna P, Thyagaraju K. Does glutathione S-transferase $\pi$ (GST- $\pi$ ) a marker protein for cancer? Mol Cell Biochem 2003;253:319-27.

33. Henderson CJ, McLaren AW, Moffat GJ, Bacon EJ, Wolf CR. $\pi$-Class glutathione S-transferase: regulation and function. Chem Biol Interact 1998;111:69-82.

34. BrabenderJ, Lord RV,Wickramasinghe K, et al. Glutathione S-transferase- $\pi$ expression is downregulated in patients with Barrett's esophagus and esophageal adenocarcinoma. J Gastrointest Surg 2002;6:359-67.

35. Ferrandina G, Scambia G, Damia G, et al. Glutathione S-transferase activity in epithelial ovarian cancer: association with response to chemotherapy and disease outcome. Ann Oncol 1997;8:343-50.

36. Stamm S, Ben-Ari S, Rafalska I, et al. Function of alternative splicing. Gene 2005;344:1 -20.

37. Bichsel VE, Liotta LA, Petricoin EF III. Cancer proteomics: from biomarker discovery to signal pathway profiling. Cancer J 2001;7:69-78.

38. Pardo M, Garcia A, Thomas B, et al. Proteome analysis of a human uveal melanoma primary cell culture by 2-DE and MS. Proteomics 2005;5:4980-93.

39. Turhani D, Krapfenbauer K, Thurnher D, Langen, H, Fountoulakis M. Identification of differentially expressed, tumor-associated proteins in oral squamous cell carcinoma by proteomic analysis. Electrophoresis 2006;27:1417-23. 